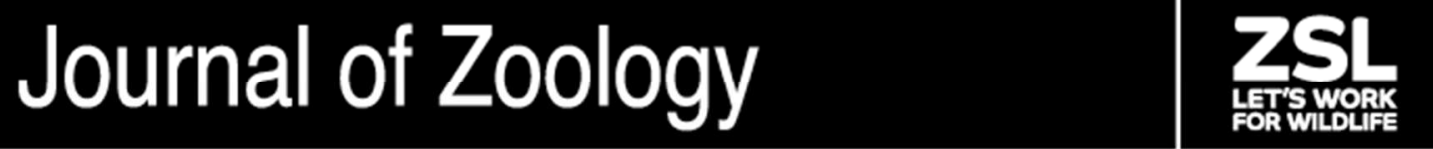

\section{Sex-specific dietary specialization in a terrestrial apex predator, the leopard, revealed by stable isotope analysis}

\begin{tabular}{|r|l|}
\hline Journal: & Journal of Zoology \\
\hline Manuscript ID & JZO-11-17-OM-321.R1 \\
\hline Manuscript Type: & Original Manuscript \\
\hline Complete List of Authors: & $\begin{array}{l}\text { Voigt, Christian; Leibniz Institute for Zoo and Wildlife Research, } \\
\text { Evolutionary Ecology Research Group } \\
\text { Krofel, Miha; University of Ljubljana, Biotechnical Faculty, Department for } \\
\text { Forestry } \\
\text { Menges, Vera; Leibniz Institut fur Zoo und Wildtierforschung eV } \\
\text { Wachter, Bettina; Leibnitz Institute for Zoo and Wildlife Research, } \\
\text { Evolutionary Ecology } \\
\text { Melzheimer, Joerg; Leibniz Institut fur Zoo und Wildtierforschung eV }\end{array}$ \\
\hline Keywords: & Dietary specialization, Namibia, predation, foraging, carnivores \\
\hline \multicolumn{2}{|c}{} \\
\hline
\end{tabular}




\section{Sex-specific dietary specialization in a terrestrial apex predator, the leopard,}

2 revealed by stable isotope analysis

3

4

5 C. C. Voigt ${ }^{1,2}$, M. $\operatorname{Krofel}^{3}$, V. Menges ${ }^{1}$, B. Wachter ${ }^{1, *} \&$ J. Melzheimer $^{1, *}$

6

7

81 Department of Evolutionary Ecology, Leibniz Institute for Zoo and Wildlife Research, Alfred-

$9 \quad$ Kowalke-Str. 17, 10315 Berlin, Germany

102 Department of Animal Behavior, Institute of Biology, Takustr. 6, 14195 Berlin, Germany

113 Department of Forestry and Renewable Forest Resources, Biotechnical Faculty, University of

12 Ljubljana, Večna pot 83, SI-1001 Ljubljana, Slovenia

$13 *$ These authors contributed equally to this work

14 Correspondence

15 Christian C. Voigt, Department of Evolutionary Ecology, Leibniz Institute for Zoo and Wildlife

16 Research, Alfred-Kowalke-Str. 17, 10315 Berlin, Germany.

17 Email: voigt@izw-berlin.de

18

19 Short title: Dietary specialization of leopards

20

21 


\section{Abstract}

23 Apex predators in terrestrial ecosystems, such as leopards in the African savanna, feed on a wide 24 variety of prey species, yet it is unknown whether individuals specialize on certain prey, and 25 whether specialization changes with body traits. Here, we asked whether individual specialization 26 of adult leopards varies with sex, body mass, body length and age classes. We used the variation 27 of stable carbon and nitrogen isotope ratios in 643 segments of whiskers as a temporal record of 28 past diets and established isotopic dietary niches for 36 adult leopards (18 males, 18 females).

29 Based on a variance analysis for stable carbon isotope ratios, we found that between-individual 30 variation was larger than within-individual variation, indicating a high degree of overall 31 specialization within the studied leopards. Female adult leopards exhibited larger isotopic dietary 32 niche widths than male adult leopards. Isotopic niche width did not vary with body mass, length 33 or age. Our data suggest a difference in the level of specialization between the sexes, which 34 might be explained by more opportunistic feeding of small-sized female leopards, most likely 35 connected with a higher use of small prey species of different isotopic composition. Inter-sexual 36 resource partitioning likely facilitates territory sharing between the sexes.

39 Key words: Dietary specialization, Namibia, predation, foraging, carnivores 40 


\section{Introduction}

42 Apex predators are important regulators of populations of prey species (Terborgh et al., 2001;

43 Salo et al., 2010) and link food webs via trophic interactions (marine and terrestrial food webs:

44 Hildebrand et al., 1999; Darimont \& Reimchen, 2002; C4 and C3 food webs: Voigt et al., 2014).

45 They are also of particular conservation interest, since many of them are in conflict with humans

46 (Inskip \& Zimmermann, 2009; Henschel, Abernethy \& White, 2011). Compared to other faunal

47 groups, apex predators are under stronger pressure from hunting, retaliatory killing in response to

48 livestock predation and anthropogenic changes of their habitats (Macdonald, Loveridge \&

49 Rabinovitz, 2010; Balme et al., 2014; Darimont et al., 2015; Krofel et al., 2015; Swanepoel et al.,

50 2014, 2015). Thus, understanding their feeding ecology is particularly rewarding. Yet, we lack a

51 thorough understanding of specialization at the individual level for most apex predators. Recent

52 research suggests that data on niche width and prey selection which is based on entire carnivore

53 populations can be misleading when individual specialization is not taken into account (Elbroch

54 et al., 2016). This might be particularly relevant in the context of human-carnivore conflicts if an

55 assumed specialization is leading to the killing of threatened carnivores (Linnell et al., 1999).

56 Also, there is a growing body of evidence on the importance of individual behavioural

57 differences (Bell, Hankison \& Laskowski, 2009; Wolf \& Weissing, 2012), including the

58 individuality of foraging behaviour in top predators (Cavalcanti \& Gese, 2010; Steyaert et al.,

59 2014; Elbroch et al., 2016). Individual specialization in predatory behaviour can have important

60 consequences for ecology and evolution, including effects on population stability, predator-prey

61 interactions, adaptive evolution and anti-predator behaviour (Wolf \& Weissing, 2012; Modlmeier

62 et al., 2014; Elbroch et al., 2016). In addition, incorporating the individual preferences of

63 predation has the potential to improve our understanding of predator-prey dynamics (Bolnick et

64 al., 2011). 
Dietary studies of top predators are hampered by the difficulty in obtaining

66 comprehensive data on the composition of consumed dietary items for given individuals, mainly

67 because of the difficulties related to consistently observing and accessing top predators. Thus,

68 most studies either remain anecdotal, semi-quantitative or biased, e.g. when based on faecal

69 samples or kill sites alone, or these studies provide only a brief temporary snapshot of what

70 predators have consumed recently (Mills, 1992; Henschel et al., 2005; Hayward et al., 2006;

71 Klare, Kamler \& Macdonald, 2011; Wachter et al., 2012). Stable isotope ratios of carbon and

72 nitrogen $\left(\delta^{13} \mathrm{C}\right.$ and $\delta^{15} \mathrm{~N}$, respectively) have been successfully used as proxies for dietary

73 specialization in predators. Past studies followed one of two approaches. They either looked at

$74 \delta^{13} \mathrm{C}$ and $\delta^{15} \mathrm{~N}$ values of tissues with different isotopic retention times, e.g. muscle, liver and

75 blood (Matich, Heithaus \& Layman, 2011; Kim et al., 2013; Voigt et al., 2014) or at values from

76 biologically inert body products with constant growth rate, i.e. tail hair, guard hair, whiskers or

77 vibrissae (Darimont \& Reimchen, 2002; Urton \& Hobson, 2005; Newsome et al., 2009; Codron

78 et al.m 2012; Lehmann et al., 2015).

79 In a marine top predator, the Californian sea otter (Enhydra lutris nereis), animals

80 exhibited highly variable $\delta^{13} \mathrm{C}$ and $\delta^{15} \mathrm{~N}$ values in vibrissae, suggesting that the study population

81 made use of almost all suitable dietary species (Newsome et al., 2009). However, variation in

82 stable isotope ratios was best explained by inter-individual effects, indicating that individuals

83 differed largely in the relative amount of consumed dietary species, i.e. individuals exhibited

84 relatively constant choices of food items. Similar findings have been reported for cheetahs

85 (Acinonyx jubatus) on commercial farmland in Namibia (Voigt et al., 2014). In grey wolves

86 (Canis lupus) of North America, inter-individual variation of $\delta^{13} \mathrm{C}$ and $\delta^{15} \mathrm{~N}$ values was high even

87 in this socially foraging top predator (Urton \& Hobson, 2005), indicating that individual

88 specialization was also independent of social group composition. In summary, previous studies 
89 highlighted the applicability of the stable isotope approach for estimating isotopic dietary niches 90 in top predators. Also, they underline that top predators make use of the full spectrum of prey 91 species at the population level, yet individuals may specialize on different prey species. However, 92 none of the previous studies investigated how specialization on isotopically different dietary 93 items may change with body mass, body length, age and sex within a top predator species. Such 94 information is not only of academic interest, but can also be important for example in the context 95 of human-carnivore conflicts and to understand intra- and inter-specific competitions in 96 carnivores.

97 Here, we studied the isotopic specialization of an apex predator in an African ecosystem, 98 the leopard (Panthera pardus), by analyzing the variation in stable isotope ratios in incrementing 99 segments of whiskers obtained from a total of 36 individuals. In leopards, whiskers grow at 0.65 100 mm per day (Mutirwara, Radloff \& Codron, 2017), i.e. a $10 \mathrm{~cm}$ whisker would be produced over 101 about 154 days. Leopards are generally characterized by a highly variable diet (Hayward et al., 102 2006; Jooste et al., 2013), which makes them a suitable model species to study interactions 103 between individual traits and dietary niche. We estimated the isotopic dietary niche width of 104 individuals based on the area encompassed by the $95 \%$ confidence intervals of Bayesian ellipses 105 established for intra-individual $\delta^{13} \mathrm{C}$ and $\delta^{15} \mathrm{~N}$ values (Newsome et al., 2007; del Rio et al., 2009). 106 If leopards feed on a variety of isotopically distinct prey species, such as grazers (high $\delta^{13} \mathrm{C}$ 107 values) and browsers (low $\delta^{13} \mathrm{C}$ values) or prey species with high or low $\delta^{15} \mathrm{~N}$ values (Voigt et al., 108 2015), the scatter plot of isotopic data from whiskers increments would be larger compared to 109 specialist leopards that feed only on a subset of aforementioned species groups. Thus, the size of 110 Bayesian ellipses based on individual $\delta^{13} \mathrm{C}$ and $\delta^{15} \mathrm{~N}$ values may inform about the level of 111 specialization across individuals. However, it is important to keep in mind that feeding on many 
112 prey species may not necessarily lead to large isotopic variance in the consumer tissue, if prey 113 species are isotopically similar (del Rio et al., 2009).

114 On the population level, we expected leopards to derive food from all available food 115 sources, indicated by a large range of $\delta^{13} \mathrm{C}$ and $\delta^{15} \mathrm{~N}$ values across individuals. On the individual 116 level, we expected small-sized leopards to depend more on smaller prey species (Sinclair et al., 117 2003), which typically consist of more different species compared to large prey species. This 118 includes juveniles of a certain species which leopards may not target as an adult prey animal. 119 Therefore, the dietary niche of small-sized leopards should be broader than the one of larger 120 leopard individuals, which are predicted to specialize on consuming larger prey species. Thus, 121 given the sexual size dimorphism in leopards we expected females to have a larger isotopic 122 dietary niche width than males. Also, based on the same argument, we expected the isotopic 123 dietary niche width to decrease with increasing body mass or length in leopards. Lastly, we tested 124 whether isotopic dietary niche width would correlate with the consumption of grazers (C4 diet) or 125 browsers (C3 diet), as indicated by $\delta^{13} \mathrm{C}$ values, or with trophic position, as indicated by $\delta^{15} \mathrm{~N}$ 126 values.

\section{Materials and Methods}

129 Field work was conducted on commercial cattle and game farmland in central Namibia $\left(22^{\circ} 00^{\prime} \mathrm{S}\right.$ 130 to $23^{\circ} 00^{\prime} \mathrm{S}$ and $16^{\circ} 40^{\prime} \mathrm{E}$ to $18^{\circ} 20^{\prime} \mathrm{E}$ ) between December 2011 and February 2016. Our study was 131 approved by the Ministry of Environment and Tourism (MET) in Windhoek, Namibia (permit 132 numbers $1514 / 2011,1689 / 2012,1813 / 2013,1914 / 2014,2067 / 2015)$. Leopards were captured in 133 box traps and then chemically immobilized with $0.08 \mathrm{mg} / \mathrm{kg}$ medetomidine hydrochloride 134 (Medetomidine $10 \mathrm{mg} / \mathrm{ml}$, Kyron Laboratories, South Africa) and $3.9 \mathrm{mg} / \mathrm{kg}$ ketamine (Ketamine $1351 \mathrm{G}$, Kyron Laboratories, South Africa) and reversed with $0.11 \mathrm{mg} / \mathrm{kg}$ atipamezole (Antisedan ${ }^{\circledR}$, 
136 Pfizer, South Africa). After immobilization, leopards were weighed with a spring scale attached 137 to a stretcher carrying the leopard (accuracy $0.1 \mathrm{~kg}$ ) and body length was measured from the tip 138 of the nose to the base of the tail (accuracy $0.5 \mathrm{~cm}$ ). We did not obtain body length measurements 139 of 2 females and 1 male and thus discarded these datasets from further statistical analysis. We 140 also had access to three leopards legally shot as problem animals of which one hunter had 141 measured the body mass of one leopard before it was skinned. We categorized the adult 142 individuals into three age classes, young adults, medium aged adults and old adults, by the wear 143 and tear of teeth and fur. Animals with no missing and broken teeth, shiny coat and/or no scars 144 were categorized as young adults, animals with a few missing and broken teeth, and/or a few 145 scars were categorized as medium aged adults and animals with several missing and broken teeth, 146 dull coat and/or several scars were categorized as old adults. To determine the degree of 147 specialization based on stable isotope ratios, we collected the longest available whisker from each 148 individual. Samples were put separately into envelopes and shipped to the stable isotope 149 laboratory of the Leibniz Institute for Zoo and Wildlife Research in Berlin, Germany under the 150 corresponding export and import CITES permits.

151 Whiskers were cleaned of external contaminants using a chloroform-methanol solution 152 (2:1) and afterwards dried in an oven over 24 hours at $50^{\circ} \mathrm{C}$. Then, whiskers were cut into small 153 segments of $0.5 \mathrm{~cm}$, each segment considered to integrate isotopically over a growth period of 8 154 days. From each segment, we put a $0.5 \mathrm{mg}$ sample in a tin capsules (IVA Analysetechnik e.K. 155 Meerbusch, Germany). Capsules were folded and then placed in an autosampler. Samples were 156 combusted and analyzed using an elemental analyzer (CE 1110 EA; Thermo Finnigan, Bremen, 157 Germany) coupled to a Delta Plus isotope ratio mass spectrometer (Thermo Finnigan, Bremen, 158 Germany) in continuous flow. Atmospheric nitrogen was used as the standard for stable nitrogen 159 isotopes and Vienna-PDB as the standard for stable carbon isotopes. The methodological 
160 approach in analyzing stable carbon and nitrogen isotope ratios has been described in detail in 161 Popa-Lisseanu et al. (2012). All stable isotope ratios are expressed in the delta notation as parts 162 per mille (\%) deviations of the sample isotope ratios from the ratios of respective international 163 standards (air nitrogen for $\delta^{15} \mathrm{~N}$ and V-PDB for $\delta^{13} \mathrm{C}$ values). Precision of measurements was 164 always better than $0.4 \%$ (one standard deviation; SD). We calculated $\delta^{13} \mathrm{C}$ and $\delta^{15} \mathrm{~N}$ values for 165 each individual separately, before the values entered the analyses.

166 Body traits of animals were compared using Student t-tests when requirements for 167 parametric testing were fulfilled. We used the element that covered the largest per mille range $168\left(\delta^{13} \mathrm{C}\right.$ values) to obtain variance measures of the intra- and inter-specific variation of the isotopic 169 composition using a one-way ANOVA. Further, isotopic dietary niche metrics were calculated 170 and plotted based on stable isotope ratios of segments for each individual whisker using the 171 SIBER package (Jackson et al. 2011) in R (version 3.3.1). Standard ellipse area (SEA) values 172 were corrected for small sample size $\left(\mathrm{SEA}_{\mathrm{c}}\right.$ ) using SIBER (Jackson et al., 2011), version 4.2, in 173 R. We defined the $95 \%$ CI of these niches as the actual boundaries of individual isotopic niches 174 during the study period (see Jackson et al., 2012). We then tested whether males and females 175 differed in mean $\mathrm{SEA}_{\mathrm{c}}$ using Student t-test. Further, we tested whether $\mathrm{SEA}_{\mathrm{c}}$ co-varied with 176 individual body parameters, such as body mass, body length and age classes using a general 177 linear model. Finally, we tested in both sexes whether SEA $\mathrm{C}$ was related to $\delta^{13} \mathrm{C}$ and $\delta^{15} \mathrm{~N}$ values 178 using Spearman correlation coefficients. Alpha values were set to 0.05. Statistics were calculated 179 with either R (R Core Team 2014) or SYSTAT (Systat Software Inc., Richmond, U.S.A.). Data is 180 presented as mean values \pm one $\mathrm{SD}$. 
183

184

185

186

187

188

189

190

191

192

193

194

195

196

197

198

199

200

201

202

203

204

205

206

\section{Results}

On average, we obtained $17.6( \pm 3.8$, range: $10-22)$ whiskers segments from male and $18.1( \pm$ 4.1, range: 12 - 29) from female leopards and measured stable isotope ratios in a total of 643 segments. Mean $\delta^{13} \mathrm{C}$ and $\delta^{15} \mathrm{~N}$ values of individual whiskers ranged over $9.2 \%$ (range: -13.4 to $19.1 \%$ ) and $5.5 \%$ (range: 8.1 to $13.6 \%$ ), respectively, in male and over $10.5 \%$ (range: -20.3 to $-9.8 \%$ ) and $4.1 \%$ (range: 8.2 to $12.3 \%$ ), respectively, in female leopards (Fig. 1 and 2). Overall, $\delta^{13} \mathrm{C}$ values of leopards averaged $-13.4 \pm 2.6 \%$ in male and $-14.1 \pm 3.1 \%$ in female individuals, and $\delta^{15} \mathrm{~N}$ values averaged $11.2 \pm 1.5 \%$ for male and $10.1 \pm 1.4 \%$ for female leopards. Following a one-way ANOVA, individuals differed significantly in the consumption of isotopically different prey $\left(F_{607,35}=32.9, P<0.001\right)$. Based on a variance component analysis, we found that between-individual variation explained $65.5 \%$ and within-individual variation $34.5 \%$ of the variation in $\delta^{13} \mathrm{C}$ values.

Adult male leopards were on average $22.6 \mathrm{~kg}$ heavier than adult female leopards (males: $57.9 \pm 8.5 \mathrm{~kg}$, females: $\left.33.8 \pm 5.3 \mathrm{~kg} ; t_{31}=9.6, P<0.001\right)$. Also, male leopards were larger than females (body length: males: $127 \pm 14 \mathrm{~cm}$; females: $114 \pm 6 \mathrm{~cm} ; \mathrm{t}_{26.7}=9.8, \mathrm{p}<0.001$ ). Twelve leopards were assigned to age class 'young adult' ( 4 males, 8 females), 21 to age class 'medium aged adult' $(12,9)$ and 3 to age class 'old adult' $(2,1)$. Male and female leopards in our study were of similar age $\left(X^{2}=1, P>0.05\right)$. According to a GLM, none of the individual traits (body mass: $F_{27.1}=0.38 ; P=0.847$, length: $F_{27,1}=0.09, P=0.772$; age class: $\left.F_{27.2}=0.87, P=0.206\right)$, except sex $\left(F_{27.1}=4.71, P=0.039\right)$ correlated with the isotopic dietary niche size SEA (see Fig. 3 for sexspecific differences in $\mathrm{SEA}_{\mathrm{c}}$ ) We then tested whether the isotopic dietary niche size varied with $\delta^{13} \mathrm{C}$ or $\delta^{15} \mathrm{~N}$ values, but detected no significant correlations for 3 out of 4 possible relationships (male: $r_{\mathrm{s}}=-0.31$ for $\delta^{13} \mathrm{C}$ values, $P>0.05 ; r_{s}=-0.134$ for $\delta^{15} \mathrm{~N}, P>0.05$; female: $r_{s}=0.07$ for $\left.\delta^{13} \mathrm{C}, P>0.05\right)$. In females, $\mathrm{SEA}_{\mathrm{c}}$ correlated negatively with $\delta^{15} \mathrm{~N}$ values $\left(r_{s}=-0.61, P<0.05\right)$. 


\section{Discussion}

209 We used the stable isotope record of whisker increments as a proxy for the dietary history and the

210 level of specialization in leopards on commercial farmland in Namibia. We used whiskers of 211 approximately 8-10 cm length, which integrates over a period of approximately 150 days when

212 assuming a growth rate of $0.65 \mathrm{~mm}$ per day reported for a single captive leopard (Mutirwara et 213 al., 2017). Growth rates of free-ranging leopard may deviate from this measurement. Here, we 214 assume that growth rates do not vary systematically across individuals of our study populations. 215 A systematic difference in growth rates between groups of individuals may alter the estimate of 216 individual specialization, yet given the large number of segments included in this study 217 (approximately 18 segments per whisker), we do not anticipate this to affect our results. Mean $218 \delta^{13} \mathrm{C}$ or $\delta^{15} \mathrm{~N}$ values of leopard whiskers were broadly distributed across the isotopic space of the 219 potential prey species that are typically found in the study area. In a previous study, Voigt and 220 colleagues (2004) listed potential prey species of cheetahs on commercial farmland in Namibia.

221 Stable isotope data varied between $-23.8 \%$ and $-12.3 \%$ for carbon and between $7.6 \%$ and 10.7

$222 \%$ for nitrogen (Voigt et al., 2014), which is within the same range of leopard isotope data of this 223 study. The large variability in isotopic data between individuals suggests that, from a population 224 perspective, leopards made use of many prey species that differed markedly in their isotopic 225 composition. Variation of $\delta^{13} \mathrm{C}$ values was large between individuals, indicating individual 226 specialization of leopards on the carbon scale. This confirms previous studies that populations of 227 apex predators consist of specialized individuals that focus on specific species within the 228 spectrum of available prey (Matich et al., 2011; Newsome et al., 2009; Voigt et al., 2014; 229 Elbroch et al., 2016; Broekhuis et al., 2018). The broad use of prey species is also consistent with 230 previous reviews conducted at various locations throughout the distribution range of leopards 
231 (Hayward et al., 2006). For example, leopards from the Western Cape in South Africa consumed 232 many small and medium-sized ungulate, rodent and bird species (Braczkowski et al., 2011). In 233 Gabon, almost $60 \%$ of the biomass consumed by leopards consisted of various ungulate species, 234 followed by diurnal primate species and large rodent species (Henschel et al., 2005). This high 235 level of flexibility in foraging behaviour may be one of the keys to the success of leopards in 236 anthropogenically modified landscapes.

237 At our study site, male leopards weighed almost twice as much as female leopards, yet 238 sexes did not differ as strongly in body length. Female and male leopards in our study came from 239 similar age classes, thus sex-specific difference in body traits in isotopic parameters could not be 240 explained by age differences. We observed that adult female leopards exhibited a larger isotopic 241 dietary niche $\left(\mathrm{SEA}_{\mathrm{c}}\right)$ width than males, which highlights that female leopards are more generalist 242 consumers than male leopards. We argue that small-sized leopards, such as most females, use 243 smaller-sized and consequently more diverse prey species, which might correlate with an increase 244 in isotopic dietary niche width. This diversity might also be linked to whether females are 245 accompanied by cubs, which might require more flexibility in the choice of prey species, also 246 depending on the age of the cubs. Furthermore, Pitman and colleagues suggested that female 247 leopards may be limited in their foraging ability due to possible interactions with larger predator 248 species, such as lions (Panthera leo) (Pitman et al. 2013).

249 We did not detect a correlation between biological variables and $\mathrm{SEA}_{\mathrm{c}}$ in female and male 250 leopards. We acknowledge that our descriptive and thus correlational approach does not allow 251 differentiating between cause and effect. Nevertheless, our results are in line with previous 252 studies that suggest larger leopards, i.e. males, hunt larger prey species more effectively (Bothma 253 \& le Riche, 1984; Bothma \& Coertze, 2004; Stander, 1997) and are probably also more 254 successful in defending their prey against kleptoparasites (Pitman et al., 2013). Overall, large 
255 individuals seem to be less dependent on hunting smaller prey. In addition to body size, males 256 may exhibit morphological adaptations that are likely connected with hunting larger prey, such as 257 the sagittal crest on top of the skull that serves as an attachment for jaw muscles (Sunquist \& 258 Sunquist, 2002). We found no correlation between $\mathrm{SEA}_{\mathrm{c}}$ and any of the two stable isotope ratios, 259 except for females for which $\mathrm{SEA}_{\mathrm{c}}$ was negatively correlated with $\delta^{15} \mathrm{~N}$ values. For $\delta^{13} \mathrm{C}$ values, 260 this pattern indicates that a specialist or generalist diet is not related to a preference for browsing 261 or grazing ungulates. If leopards would be specialist for grazers (C4 plant diet) or browers (C3 262 plant diet), we would expect a correlation between $\mathrm{SEA}_{\mathrm{c}}$ size and high or low $\delta^{13} \mathrm{C}$ values, 263 respectively. In contrast, our data suggests that leopards may specialize on any prey species, i.e. 264 grazers or browsers alone, or a mix of both. The correlation between SEAc and $\delta^{15} \mathrm{~N}$ values in 265 female leopards might be related to more specialized female leopards foraging on prey species 266 with higher $\delta^{15} \mathrm{~N}$ values, possibly on those at a higher tropic level.

267 Observed differences in feeding patterns between sexes could have several ecological and 268 management implications. First, inter-sexual differences in diet may result in some level of intra269 specific resource partitioning (Hayward et al., 2006), which could reduce competition among 270 leopards. Reduced inter-sexual food competition has been suggested to be one of the main drivers 271 for the evolution of sexual size dimorphism in carnivores (Dayan \& Simberloff, 1996). We 272 suggest that the observed connection between diet, body mass and sex of leopards could be such 273 a case. This is not unexpected given that leopards exhibit a land tenure-social system, in which 274 mature individuals typically exclude conspecifics of the same sex from large parts of their 275 territory, while territories usually overlap extensively between the sexes (Bailey, 1993; Stander et 276 al., 1997). A similar pattern could be expected for resource partitioning between adults and sub277 adults, because in leopards offspring may remain within their natal home ranges several years 
278 after separating from their mothers (Fattebert et al., 2015). Our study, however, did not include 279 samples from sub-adults, thus further research is needed to investigate this idea.

280 Since adult female leopards rely on more diverse prey species, their predation effects on

281 prey populations are expected to be more diluted compared to that of adult male leopards.

282 Therefore, the impact of females on a given prey species should be lower compared to the one of 283 males. This is relevant from a game management perspective, as well as for livestock 284 depredations. The relatively higher individual specialization of males on prey species suggests 285 that males have a higher potential to specialize on hunting livestock or endangered wildlife 286 species that may get repeatedly targeted by the same individual leopard (Bailey, 1993). This is 287 confirmed by the higher proportion of males among leopards associated with livestock 288 depredations (Linnell et al., 1999; but see Kerth et al., 2013).

289 Overall, the high degree of specialization and high individual variation in the isotopic 290 composition of the consumed diets in our data suggest that diet analyses need to be interpreted 291 with caution. Datasets from a small number of individuals can lead to biased results which are not 292 representative for the entire population. This may be particularly relevant for GPS telemetry 293 studies on leopards, during which leopard location clusters are used to find prey remains and 294 which are typically limited to small numbers of monitored individuals. Ensuring representative 295 sample sizes should therefore be a prerequisite for such studies. Alternatively, we suggest 296 combining results from several small-scale GPS studies in order to obtain reliable information 297 based on sufficient sample sizes, ideally with evenly distributed sex and age classes, and thus 298 improve leopard dietary research. Furthermore, studies in which telemetry data are used to locate 299 prey remains are also potentially biased towards larger prey species and miss possibly important 300 small prey species as part of the diet (Bailey, 1993; Mills, 1992, Pitman et al, 2012). Only with a 301 very labour intense sampling regime Pitman et al. (2013) were able to minimise the bias against 
302 smaller prey. Thus, such studies should be combined with scat analyses to detect also small prey 303 species (e.g. Pitman et al., 2013; Martins et al., 2011; Tambling et al., 2012). Isotope analyses 304 overcome these difficulties, and samples obtained from individuals with respective information 305 on their body mass, age and sex of the predator can provide further insights into the importance 306 of these parameters in the foraging behaviour, as we demonstrated in the case of the leopard in 307 Namibia.

308 In summary, we showed that male and female leopards use a broad isotopic dietary niche 309 on commercial farmland in Namibia, and isotopic dietary niches were larger in females compared 310 to males. We argue that the more variable isotopic niche width of female leopards might be 311 associated with the consumption of smaller and isotopically more variable prey species compared 312 with the prey spectrum of male leopards. Differences in isotopic niche width between males and 313 females may allow both sexes to use the same area for foraging without necessarily engaging in 314 exploitation competition.

\section{Acknowledgments}

317 We thank the Namibian Ministry of Environment and Tourism for permission to conduct the 318 study, and the Seeis and Auas Oanob Conservancies for cooperation. We further thank Dirk 319 Bockmühl, Sonja Heinrich, Ivan Palmegiani, Ruben Portas and Bernd Wasiolka for help with the 320 field work, immobilization of leopards and collection of whiskers. We also thank Karin Grassow 321 and Doris Fichte for help in the analysis of stable isotopes. This work was financed by the 322 Messerli Foundation in Switzerland, and the German Academic Exchange Service (DAAD) and 323 the Leibniz Institute for Zoo and Wildlife Research in Germany. M.K. was additionally supported 324 by the Slovenian Research Agency (P4-0059). We thank three anonymous reviewers for 325 providing helpful comments on an earlier draft of this manuscript. 
326

327

328

329

330

331

332

333

334

335

336

337

338

339

340

341

342

343

344

345

346

347

348

\section{References}

Bailey, T. N. (1993). The African leopard: a study of the ecology and behavior of a solitary felid. Columbia University Press, New York.

Balme, G. A., Lindsey, P. A., Swanepoel, L. H. \& Hunter, L. T. B. (2014). Failure of research to address the rangewide conservation needs of large carnivores: Leopards in South Africa as a case study. Conserv. Lett. 7, 3-11.

Bell, A. M., Hankison, S. J. \& Laskowski, K. L. (2009). The repeatability of behaviour: a metaanalysis. Anim. Behav. 77, 771-783.

Bolnick, D. I., Amarasekare, P., Araújo, M. S., Bürger, R., Levine, J. M., Novak, M., Rudolf, V. H. W., Schreiber, S. J., Urban, M. C. \& Vasseur, D. (2011). Why intraspecific trait variation matters in community ecology. Trends Ecol. Evol., 26, 183-192.

Bothma, J. D. P. and Le Riche, E. A. (1984). Aspects of the ecology and the behaviour of the leopard Panthera pardus in the Kalahari Desert. Koedoe 27(2), 259-279.

Bothma, J. D. P. and Coertze, R. J. (2004). Scent-marking frequency in southern Kalahari leopards. South African J. Wildl. Res. 34, 163-169.

Broekhuis, F., Thuo, D., \& Hayward, M. W. (2018). Feeding ecology of cheetahs in the Maasai Mara, Kenya and the potential for intra $\square$ and interspecific competition. J. Zool. 304, 6572.

Braczkowski, A., Watson, L., Coulson, D., \& Randall, R. (2012). Diet of leopards in the southern Cape, South Africa. Afr. J. Ecol. 50(3), 377-380.

Cavalcanti, S. M. C. \& Gese, E. M. (2010). Kill rates and predation patterns of jaguars (Panthera onca) in the southern Pantanal, Brazil. J. Mammal. 91, 722-736.

Clarke K. R. and Gorley R. N. (2006). PRIMER v6: User Manual PRIMER-E, Plymouth. 
349 Darimont, C. T. and Reimchen, T. E. (2002). Intra-hair stable isotope analysis implies seasonal 350 shift to salmon in gray wolf diet. Can. J. Zool. 80(9), 1638-1642.

351 Darimont, C. T., Fox, C. H., Bryan, H. M. \& Reimchen, T. E. (2015). The unique ecology of 352 human predators. Science, 349, 858-860.del Rio MC, Sabat P, Anderson-Sprecher R, 353 Gonzalez SP (2009) Dietary and isotopic specialization: the isotopic niche of three 354 Cinclodes ovenbirds. Oecologia 161(149), 149-159.

355 Del Rio, C. M., Sabat, P., Anderson-Sprecher, R., \& Gonzalez, S. P. (2009). Dietary and isotopic 356 specialization: the isotopic niche of three Cinclodes ovenbirds. Oecologia, 161, 149-159.

357 Farhadinia, M. S., Kaboli, M., Karami, M., \& Farahmand, H. (2014). Patterns of sexual 358 dimorphism in the Persian leopard (Panthera pardus saxicolor) and implications for sex 359 differentiation. Zool. Middle East 60(3), 195-207.

360 Fattebert, J., Balme, G., Dickerson, T., Slotow, R. \& Hunter, L. (2015). Density-Dependent Natal 361 362 Dispersal Patterns in a Leopard Population Recovering from Over-Harvest. Plos One 10, e0122355.

363 Hayward, M. W., Henschel, P., O'Brien, J., Hofmeyr, M., Balme, G. \& Kerley, G. I. H. (2006). 364 Prey preferences of the leopard (Panthera pardus). J. Zool. 270(2), 298-313.

365 Henschel, P., Abernethy, K. A., \& White, L. J. T. (2005). Leopard food habits in the Lope National Park, Gabon, Central Africa. Afr. J. Ecol. 43(1), 21-28.

367 Henschel, P., Hunter, L. T., Coad, L., Abernethy, K. A., \& Mühlenberg, M. (2011). Leopard prey 368 choice in the Congo Basin rainforest suggests exploitative competition with human 369 bushmeat hunters. J. Zool. 285(1), 11-20.

370 Hilderbrand, G. V., Schwartz, C. C., Robbins, C. T., Jacoby, M. E., Hanley, T. A., Arthur, S. M., 371 \& Servheen, C. (1999). The importance of meat, particularly salmon, to body size, 
372

373

374

375

376

377

378

379

380

381

382 383

384

385

386

387

388

389

390

391

392

393

394

population productivity, and conservation of North American brown bears. Can. J. Zool. 77(1), 132-138.

Inskip, C. and Zimmermann, A. (2009). Human-felid conflict: a review of patterns and priorities worldwide. Oryx 43(01), 18-34.

Jackson, A. L., Parnell, A. C., Inger R. \& Bearhop, S. (2011). Comparing isotopic niche widths among and within communities: SIBER - Stable Isotope Bayesian Ellipses in R. J. Anim. Ecol. 80, 595-602.

Jackson M. C., Donohue I., Jackson A. L., Britton J. R., Harper D. M., Grey J. (2012). Population-level metrics of trophic structure based on stable isotopes and their application to invasion ecology. PLoS One 7, e31757.

Jooste, E., Hayward, M. W., Pitman, R. T., \& Swanepoel, L. H. (2013). Effect of prey mass and selection on predator carrying capacity estimates. European journal of wildlife research, $\mathbf{5 9}, 487-494$.

Kerth, G., Gusset, M., Garbely, J., König, B., Gabanapelo, T. \& Schiess-Meier, M. (2013). Genetic sexing of stock-raiding leopards: not only males to blame. Cons. Genetics Res. 5(4), 1101-1105.

Kim S. L., Tinker M. T., Estes J. A. \& Koch P. L. (2013). Ontogenetic and among-individual variation in foraging strategies of northeast pacific white sharks based on stable isotope analysis. PLoS One 7(9):e45068.

Klare, U., Kamler, J. F., \& Macdonald, D. W. (2011). A comparison and critique of different scat-analysis methods for determining carnivore diet. Mamm. Rev. 41(4), 294-312.

Krofel, M., Treves, A., Ripple, W. J., Chapron, G. \& Lopez-Bao, J. V. (2015). Hunted carnivores at outsized risk. Science 350, 518-519. 
395 Lehmann, D., Mfune, J. K. E., Gewers, E., Brain, C., \& Voigt, C. C. (2015). Individual variation 396 of isotopic niches in grazing and browsing desert ungulates. Oecologia 179(1), 75-88.

397 Linnell, J. D. C., Odden, J., Smith, M. E., Aanes, R. \& Swenson, J. E. (1999). Large carnivores 398 that kill livestock: do "problem individuals" really exist? Wildl. Soc. Bull. 27, 698-705.

399 Macdonald, D. W., Loveridge, A. J. \& Rabinowitz, A. (2010). Felid futures: crossing disciplines, $400 \quad$ borders and generations. Biology and conservation of wild felids, 599.

401 Martins, Q., Horsnell, W. G. C., Titus, W., Rautenbach, T. \& Harris, S. (2011). Diet

402 determination of the Cape Mountain leopards using global positioning system location $403 \quad$ clusters and scat analysis. J. Zool. 283, 81-87.

404 Matich, P., Heithaus, M. R., Layman, C. A. (2011). Contrasting patterns of individual 405 specialization and trophic coupling in two marine apex predators. J. Anim. Ecol. 80, 294$406 \quad 305$.

407 Mills, M.G.L. (1992). A comparison of methods used to study food habits of large African 408 carnivores. Wildlife 2001: Populations (eds D.R. McCullough \& R.H. Barrett), pp. 1112409 1123. Elsevier Applied Science, London and New York.

410 Modlmeier, A. P., Keiser, C. N., Watters, J. V., Sih, A. \& Pruitt, J. N. (2014). The keystone 411 individual concept: an ecological and evolutionary overview. Anim. Behav. 89, 53-62.

412 Mutirwara, R., Radloff, F. G. T. \& Codron, D. (2017). Growth rate and stable carbon and 413 nitrogen isotope trophic discrimination factors of lion and leopard whiskers. Rapid Comm. 414 Mass Spectr., in press. Doi: 10.1002/cm.8003

415 Newsome, S. D., Tinker, M. T., Monson, D. H., Oftedal, O. T., Ralls, K., Staedler, M. M., Fogel, 416 M. L. \& Estes, J.A. (2009). Using stable isotopes to investigate individual diet 417 specialization in California sea otters (Enhydra lutris nereis). Ecology 90, 961-974. 
418 Pitman, R. T., Swanepoel, L. H., and Ramsay, P. M. (2012). Predictive modelling of leopard 419 predation using contextual Global Positioning System cluster analysis. J. Zool. 288, 222$420 \quad 230$

421 Pitman, R. T., Kilian, P. J., Ramsay, P. M., \& Swanepoel, L. H. (2013). Foraging and habitat 422 specialization by female leopards (Panthera pardus) in the Waterberg Mountains of South Africa. South African J. Wildl. Res. 43(2), 167-176.

424 Pitman, R. T., Mulvaney, J., Ramsay, P. M., Jooste, E., and Swanepoel, L. H. (2013). Global 425 Positioning System - located kills and faecal samples: a comparison of leopard dietary $426 \quad$ estimates. J. Zool. 292, 18-24.

427 Popa-Lisseanu A. G., Soergel, K., Luckner, A., Wassenaar, L. I., Ibáñez, C., Ciechanowski, M., 428 Görföl, T., Niermann, I., Beuneux, G., Myslajek, R., Juste, J., Fonderflick, J., Kramer429 Schadt, S., Kelm, D. H. \& Voigt, C. C. (2012). A triple isotope approach to predict $430 \quad$ breeding origins of European bats. PLoS One 7, e38083

431 R Core Team (2014). R: A Language and Environment for Statistical Computing. R Foundation 432 for Statistical Computing, Vienna, Austria.

433 Salo, P., Banks, P. B., Dickman, C. R. \& Korpimäki, E. (2010). Predator manipulation 434 experiments: impacts on populations of terrestrial vertebrate prey. Ecol. Monogr. 80(4), $435 \quad 531-546$.

436 Sinclair, A. R. E., Mduma, S. \& Brashares, J. S. (2003). Patterns of predation in a diverse 437 predator-prey system. Nature 425, 288-290.

438 Stander, P. E., Haden, P. J., Kaqece \& Ghau (1997). The ecology of asociality in Namibian 439 leopards. J. Zool. 242, 343-364. 
440 Steyaert, S. M. J. G., Kindberg, J., Jerina, K., Krofel, M., Stergar, M., Swenson, J. E. \&

441 Zedrosser, A. (2014). Behavioral correlates of supplementary feeding of wildlife: Can

442 general conclusions be drawn? Basic Appl. Ecol. 15, 669-676.

443 Sunquist, M. E. \& Sunquist, F. (2002). Wild Cats of the World. University of Chicago Press, 444 Chicago, U.S.A.

445 Swanepoel, L. H., Somers, M. J., van Hoven, W., Schiess-Meier, M., Owen, C., Snyman, A., 446 Martins, Q., Senekal, C., Camacho, G., Boshoff, W. \& Dalerum, F. (2015). Survival rates 447 and causes of mortality of leopards Panthera pardus in southern Africa. Oryx 49, 595$448 \quad 603$.

449 Swanepoel, L. H., Lindsey, P., Somers, M. J., van Hoven, W. \& Dalerum, F. (2014). The relative 450 importance of trophy harvest and retaliatory killing for large carnivores; a case study on 451 South African leopards. South Afr. J. Wildl. Res. 44, 115-134.

452 Tambling, C. J., Laurence, S. D., Bellan, S. E., Cameron, E. Z., du Toit, J. T., \& Getz, W. M. 453 (2012). Estimating carnivoran diets using a combination of carcass observations and scats 454 from GPS clusters. Jour. Zool., 286, 102-109. http://doi.org/10.1111/j.1469$455 \quad$ 7998.2011.00856.x

456 Terborgh, J., Lopez, L., Nunez, P., Rao, M., Shahabuddin, G., Orihuela, G., Riveros, M., 457 Ascanio, R., Adler, G. H., Lambert, T. D. \& Balbas, L. (2001). Ecological meltdown in 458 predator-free forest fragments. Science 294(5548), 1923-1926.

459 Urton, E. J. M. \& Hobson, K. A. (2005). Intrapopulation variation in gray wolf isotope (d15N 460 and d13C) profiles: implications for the ecology of individuals. Oecologia 145, 317-326.

461 Voigt C. C., Thalwitzer S., Melzheimer J., Blanc A.-S., Jago M. \& Wachter, B. (2014). The 462 conflict between cheetahs and humans on Namibian farmland elucidated by stable isotope 463 diet analysis. PLoS One 9(8), e101917. 
1

2

3

4

5

6

7

8

9

10 11

464 Wachter, B., Blanc, A. S., Melzheimer, J., Höner, O. P., Jago, M. \& Hofer, H. (2012). An 465 advanced method to assess the diet of free-ranging large carnivores based on scats. PloS $466 \quad$ One $7(6)$, e38066.

467 Weise, F., Lemeris, J., Stratford, K., Vuuren, R., Munro, S., Crawford, S., Marker, L., Stein, A. 468 (2015). A home away from home: insights from successful leopard (Panthera pardus) 469 translocations. Biodiversity \& Conservation, 24(7), 1755-1774. doi:10.1007/s10531-015$470 \quad 0895-7$

471 Wolf, M. \& Weissing, F.J . (2012). Animal personalities: consequences for ecology and $472 \quad$ evolution. Trends Ecol. Evol. 27, 452-461.

473 


\section{$474 \quad$ Figure legends}

475 Figure 1: Stable carbon $\left(\delta^{13} \mathrm{C}\right)$ and nitrogen isotope ratios $\left(\delta^{15} \mathrm{~N}\right)$ in subsequent segments of 476 leopard whiskers of 18 males (blue color; A, B) and 18 females (red color; C, D). Individual 477 leopards are indicated by different lines.
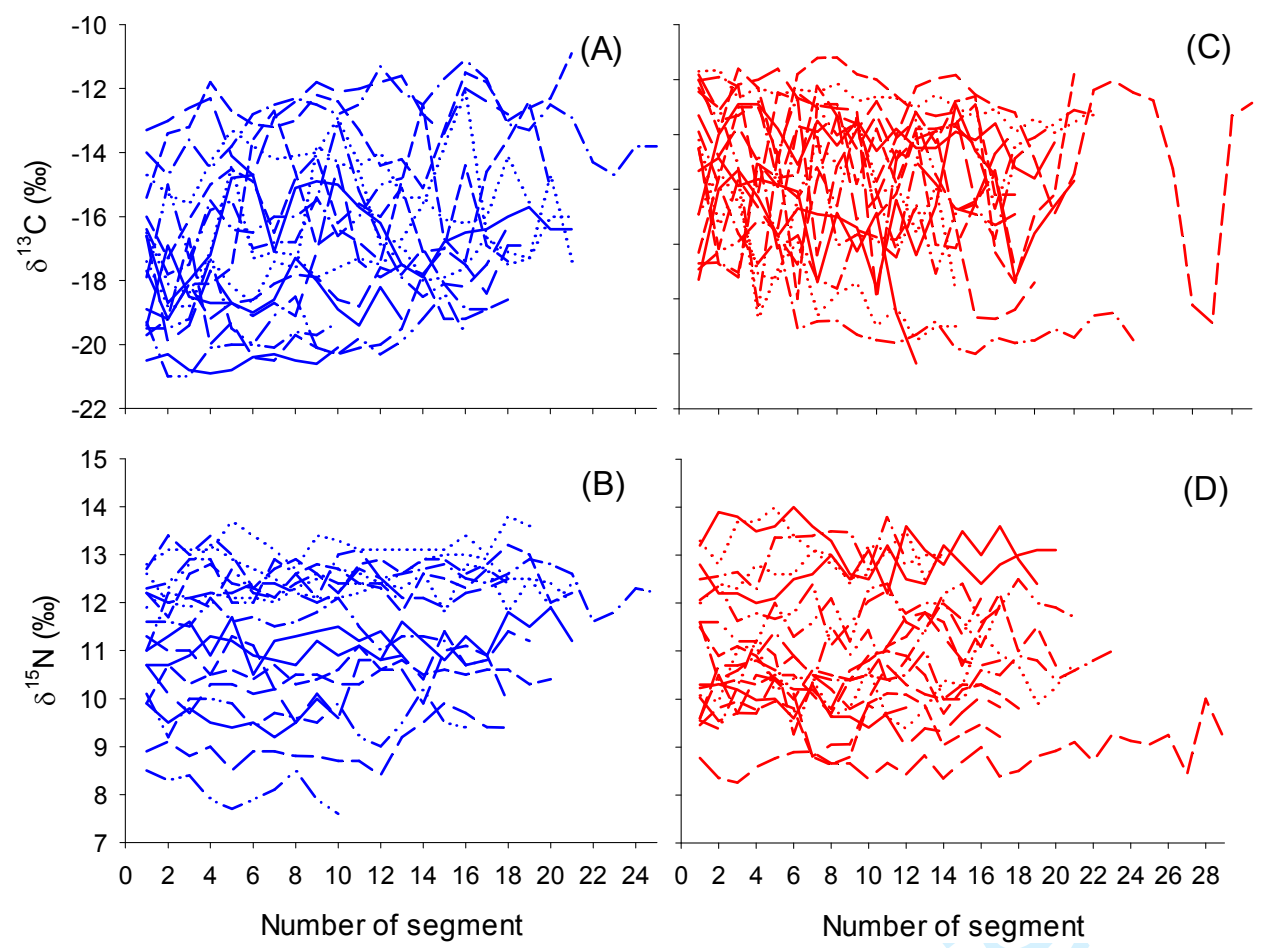

478

Number of segment 
1

2

7

8

9

10

11

12

13

14

15

16

17

18

479 Figure 2: Bivariate plot of stable carbon and nitrogen isotope ratios in segments of whiskers 480 collected from 18 male (A) and 18 female leopards (B). Individual leopards are indicated by 481 differently colored symbols and lines.
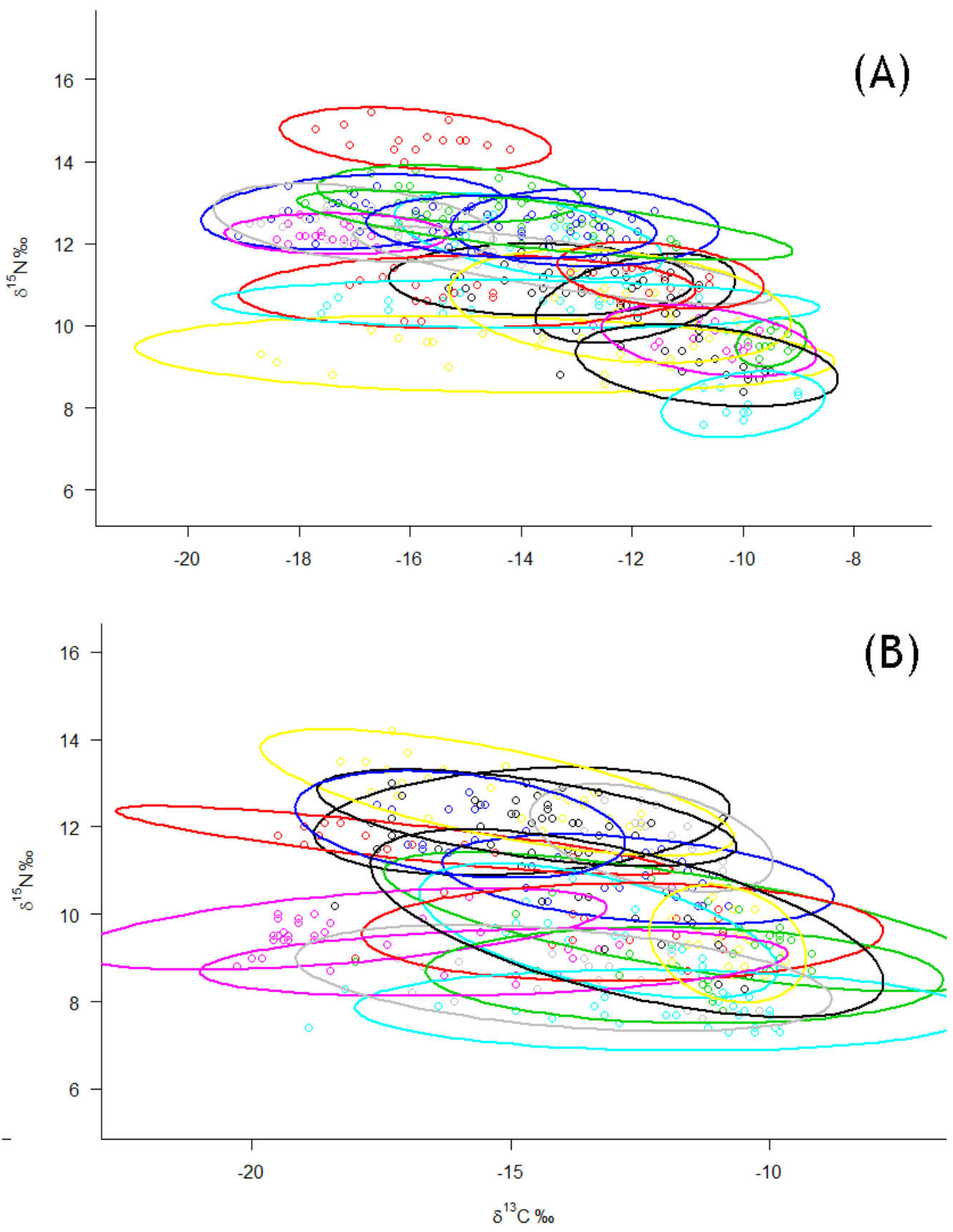

482

483

484 
485 Figure 3: Standard ellipsoid areas $\left(\mathrm{SEA}_{\mathrm{c}}\right)$ as a measurement for isotopic dietary niche width, for 48618 male and 18 female adult leopards.

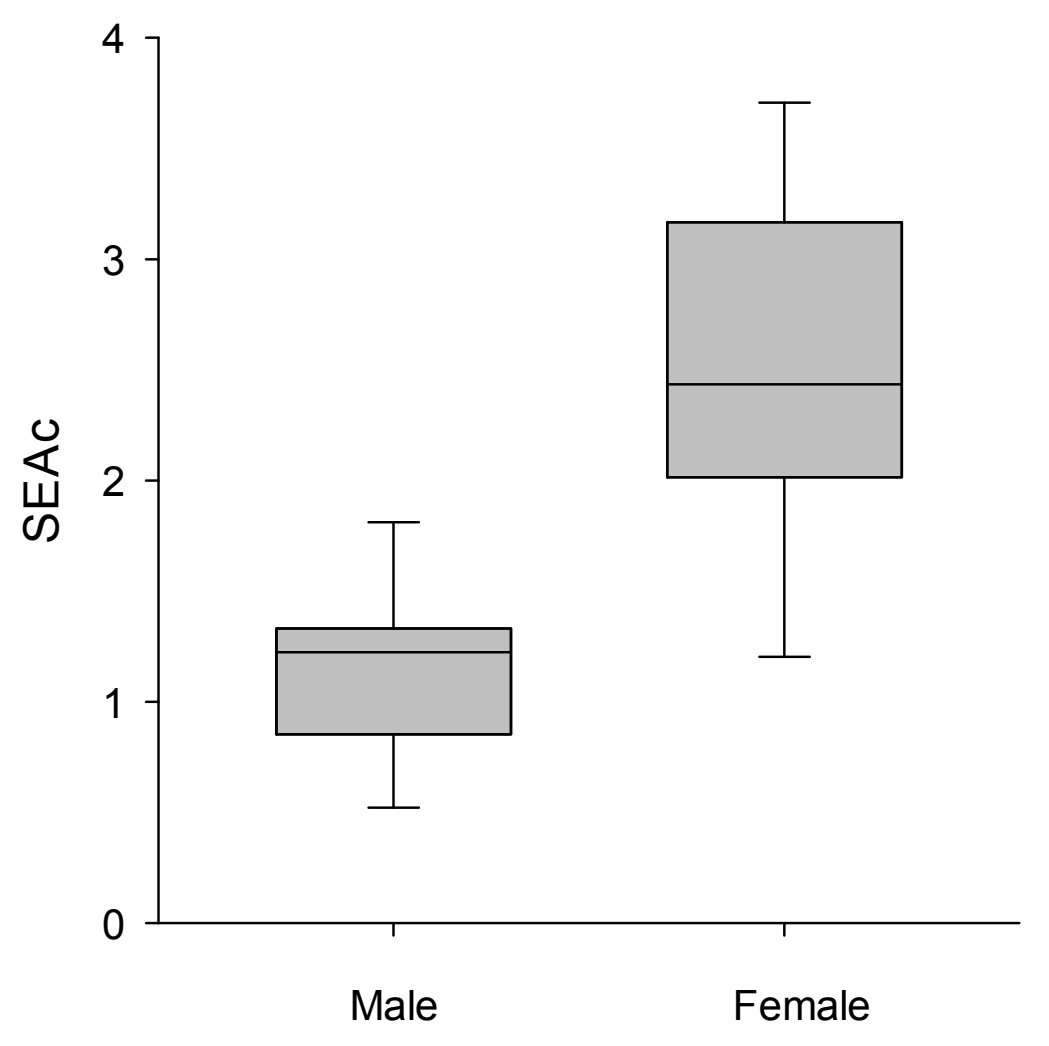


2

3488

4

5

6

7

8

9

10

11

12

13

14

15

16

17

18

19

20

21

22

23

24

25

26

27

28

29

30

31

32

33

34

35

36

37

38

39

40

41

42

43

44

45

46

47

48

49

50

51

52

53

54

55

56

57

58

59

60

JZO submitted manuscript 